Jurnal Indonesia Sosial Teknologi: p-ISSN: 2723 - 6609

e-ISSN : 2745-5254

Vol. 2, No. 1 Januari 2021

\title{
STRATEGI KOMUNIKASI PEMASARAN SCOOP DAN SKOOP DALAM MEMBANGUN BRAND IMAGE
}

\section{Hasim dan Prisnurulia Apriliani}

Program Studi Ilmu Komunikasi, Universitas Kebangsaan

Email: hasim.kbm@gmail.com

\begin{abstract}
Marketing communication has a function as a tool to influence potential consumers, companies actively promote with the aim of attracting as many consumers as possible, if you look at the account pages of other companies, you can generally find various forms of offers, advertisements, promotions, etc. is to market its products and attract visitors or consumers. Scoop \& skoops company under the ownership of Brownies Amanda which is engaged in light food, namely ice cream and already has 5 branches spread across the city of Bandung. Not only ice cream scoops \& skoops also have other menus ranging from appetizers to desserts and drinks, but scoop \& skoops make ice cream the main menu. Scoop \& Skoops is a large business actor, therefore the marketing communication strategy has a very important role to achieve the goals of scoop \& skoops and also in developing its business. The tighter competition in the ice cream business in Indonesia has fostered company competition in offering products with various variants to consumers, this is of course to increase sales and encourage Scoop \& Skoops owners to be tighter in promoting their products. Scoop \& Skoops is an ice cream shop that provides online sales using Instagram social media as a medium for promotional activities by utilizing photo uploads of products and also to build consumer confidence to keep buying Scoop \& Skoops products. The purpose of this research is to find out how Scoop \& Skoops' Instagram social media accounts in building brand image. This research was designed qualitatively with a qualitative descriptive approach paradigm, by collecting data through interviews, observation, literature study, documentation and internet searching. The speakers in this study were Marketing Scoop \& Skoops and active followers of the Instagram account @ scoop.and.skoops. The result of this research is that the marketing communication strategy carried out by Scoop \& Skoops focuses more on promoting through Instagram social media only, and its marketing communication strategy is more related to using the marketing mix (Marketing Mix).
\end{abstract}

Keyword : Marketing Communication, Instagram, Brand Image

\section{Abstrak}

Komunikasi pemasaran mempunyai fungsi sebagai alat untuk mempengaruhi calon konsumen, perusahaan melakukan promosi secara aktif dengan tujuan menarik sebanyak mungkin konsumen, jika melihat di halaman akun perusahaan-perusahaan yang lain pada umumnya dapat dijumpai berbagai macam bentuk penawaran, iklan, promosi, dan sebagainya yang tujuannya adalah untuk memasarkan produknya dan 
menarik pengunjung atau konsumen. Scoop \& skoops perusahaan dibawah kepemilikan Brownies Amanda yang bergerak dalam bidang makan ringan yaitu es krim dan sudah memiliki 5 cabang yang tersebar di Kota Bandung. Tidak hanya es krim scoop \& skoops juga memiliki menu lain mulai dari appetizer hingga dessert dan minuman namun scoop \& skoops menjadikan es krim sebagai menu utamanya. Scoop \& Skoops merupakan pelaku usaha besar maka dari itu strategi komunikasi pemasaran mempunyai peran yang sangat penting untuk mencapai tujuan scoop \& skoops dan juga dalam menggembangkan usahanya. Semakin ketatnya persaingan bisnis es krim di Indonesia menumbuhkan persaingan perusahaan dalam menawarkan produk dengan berbagai varian kepada para konsumen, hal ini tentunya untuk meningkatkan penjualan dan mendorong pemilik Scoop \& Skoops semakin kencang dalam mempromosikan produknya tersebut. Scoop \& Skoops merupakan toko es krim yang menyediakan penjualan online menggunakan media sosial instagram sebagai media untuk aktivitas promosi dengan memanfaatkan unggahan foto produk-produk dan juga untuk membangun kepercayaan konsumen agar tetap membeli produk Scoop \& Skoops. Tujuan penelitian ini adalah untuk mengetahui bagaimana akun media sosial Instagram Scoop \& Skoops dalam membangun brand image. Penelitian ini didesain secara kualitatif dengan paradigma pendekatan deskriptif kualitatif, dengan mengumpulkan data melalui wawancara, observasi, studi pustaka, dokumentasi dan internet searching. Narasumber dalam penelitian ini adalah Marketing Scoop \& Skoops dan followers aktif akun Instagram @scoop.and.skoops. Hasil penelitian ini adalah strategi komunikasi pemasaran yang dilakukan Scoop \& Skoops lebih berfokus mempromosikan melalui media sosial Instagram saja, dan strategi komunikasi pemasarannya lebih banyak berkaitan dengan menggunakan bauran pemasaran (Marketing Mix).

Kata kunci: Komunikasi pemasaran, Instagram, Citra merek

\section{Pendahuluan}

Perkembangan teknologi yang semakin pesat di era modern seperti sekarang ini, sangat mempengaruhi gaya hidup manusia untuk memenuhi kebutuhan sehari-hari seperti makan dan minum, keberadaan teknologi yang semakin canggih akan membantu manusia lebih mudah untuk menyediakan atau memenuhi kebutuhan hidup secara mandiri dan cepat, perkembangan teknologi ini secara umum dapat disebut sebagau new media. Secara sederhana new media merupakan media yang menggunakan internet, media online berbasis teknologi, berkarakter fleksibel, dan dapat berfungsi secara pribadi maupun secara umum.

(Hermawan, 2012) dalam buku E-Business \& E-Commerce menjelaskan Internet adalah komunikasi jaringan, komunikasi global yang menghubungkan seluruh komputer di dunia meskipun berbeda sistem dan mesin. Penjelasan tersebut menggambarkan aktifitas interaksi manusia yang tidak terbatas pada tempat atau wilayah tertentu, dengan adanya komunikasi jaringan ini akan lebih memudahkan segala aktifitas manusia. Perkembangan komunikasi jaringan yang semakin modern manusia dapat memanfaatkan untuk mempermudah kebutuhan komunikasi baik untuk kepentingan pribadi maupun kepentingan kelompoknya atau organisasi yang pada awalnya komunikasi bersifat terbatas pada hal-hal tertentu saja namun sekarang jalinan komunikasi bisa dikatakan tanpa batas. 
Mengutip data dari situs web WeareSocial dan Hootsuite lanskap digital dunia 2020, pengguna internet diseluruh dunia telah mencapai angka 4,5 milyar orang. Angka ini menunjukkan bahwa pengguna internet telah mencapai lebih dari 60 persen penduduk dunia atau lebih dari separuh populasi bumi. Berdasarkan data dari sumber tersebut penggunaan jaringan internet sangat besar dan diyakini banyak pihak akan merubah pola hidup manusia, perubahan pola hidup yang semula konvensional akan beralih ke pola hidup secara online atau digital. Demikian halnya dengan tren pemasaran di dunia yang semula dilakukan secara offline kini banyak yang telah beralih ke pemasaran secara online.

E-commerce merupakan konsep dari pemasaran global yang digambarkan sebagai proses jual beli barang atau jasa pada dunia online atau pertukaran informasi internet (Turban et al., 2017). E-commerce atau perdagangan elektronik sejalan dengan perjalanan waktu pada saat ini mengalami banyak perubahan, hal ini dapat dikarenakan adanya perkembangan teknologi, dengan demikian para pedagang membuat inovasi penjualan produk dengan menyesuaikan perkembangan teknologi terbaru dengan tujuan untuk lebih mempermudah dalam bertransaksi dengan pembelianya tanpa mengganggu aktifitas utama sangat padat.

(Hermawan, 2012) menjelaskan, Media Sosial adalah teknologi yang mobile dan berbasis web, yang mendorong interaksi diantara pihak-pihak yang menggunakannya. Media sosial dalam perannya saat ini memberikan manfaat pada pengunannya untuk berbagi pesan, foto, video, lokasi dan lain-lain. Inovasi pemasaran produk pada saat ini yang sedang mengalami peningkatan secara signifikan di Indonesia adalah munculnya inovasi penjualan secara online di media sosial, berdasarkan pengamatan awal peneliti media sosial yang banyak digunakan masyarakat Indonesia yaitu media sosial instagram.

Berdasarkan data yang dikutip Socialbakers; pada November 2019, jumlah pengguna aktif bulanan Instagram di Indonesia dilaporkan telah mencapai 61.610.000 artinya, 22,6 persen, atau nyaris seperempat total penduduk Indonesia, adalah pengguna Instagram. (https://socialbakers.com/statistic//). Pengunaan instagram ini terbilang cepat, bahkan perkembangan Instagram lebih baik dibandingkan Google+ pada kuartal terakhir, Instagram memiliki peningkatan sebesar 35 persen. Sedangkan Google+ hanya 5\% (dikutip dari https://www.beritateknologi.com/) (Utomo, 2013).

Berdasarkan riset yang dilakukan instagram dan firma konsultan bisnis IPSOS, 52 persen UKM Indonesia memilih instagram sebagai medium promosi untuk mengarahkan pelanggan ke situs web mereka. Data itu dihimpun dari 3.000 pengguna Instagram dan 500 UMKM dari seluruh Indonesia. Artinya instagram menjadi media paling sukses untuk berjualan, hal ini dikarenakan Instagram menyediakan fitur menarik yang dapat mendongkrak bisnis (dikutip dari https://tekno.kompas.com//).

Dijelaskan (Machfoedz, 2010) pemasaran modern memerlukan lebih dari sekedar pengembangan produk yang baik, penetapan harga yang menarik dan ketersediaan bagi konsumen sasaran. Sejalan dengan pernyataan Machfoedz, pemasaran secara modern pada sekarang ini tidak lagi sekedar menentukan hal-hal umum seperti produk, penetapan harga dan distribusi yang merupakan bauran ekonomi namun perusahaan diharapkan dapat berbuat lebih daripada itu, salah satu diantaranya membangun komunikasi dengan konsumen. Pemasaran secara modern pada saat ini telah beralih ke digital (online) ini lebih prospektif karena memungkinkan para calon pelanggan potensial memperoleh berbagai macam informasi mengenai produk dan dapat berinteraksi melalui teknologi komunikasi dan informasi dalam jaringan internet. 
Scoop \& skoops merupakan perusahaan di bawah kepemilikan Brownies Amanda yang bergerak dalam bidang makan ringan yaitu es krim di Kota Bandung. Scoop \& skoops sudah memiliki 5 cabang yang tersebar di Kota Bandung. Produk yang ditawarkan yaitu ada 24 varian rasa, Es krim original diantaranya Strawberry, Chocolate, Vanilla, Green tea, Brownies, Manggo dan lain-lain, Juga es krim premium diantaranya Rujak, Cheese, Charcoal dan lain-lain. Scoop \& Skoops sendiri memiliki dessert semi gelato yang rendah lemak, scoop \& skoops memilih semi gelato sebagai konsep dessertnya untuk menonjolkan keunggulan dari es krim dan gelato tersebut, Tidak hanya es krim scoop \& skoops juga memiliki menu lain mulai dari appetizer hingga dessert dan minuman namun scoop \& skoops menjadikan es krim sebagai menu utamanya.

Platform media sosial yang digunakan sebagai sarana media pemasaran pebisnis pemilik toko es krim Scoop \& skoops yaitu instagram, observasi awal peneliti pemasaran online melalui instagram ini dipilih karena saat ini instagram menjadi sebuah aplikasi sosial yang populer dikalangan pengguna telefon pintar (Smartphone). Es krim merupakan makanan selingan yang diminati berbagai tingkat/ kalangan, Scoop \& skoops ini memanfaatkan media sosial instagram untuk menjangkau para konsumen di berbagai tempat di Indonesia dan secara khsusu di Kota Bandung (Nasrullah, 2015).

Komunikasi pemasaran yang dilakukan dengan baik dan masif di sosial media akan membuat produk-produk yang dipasarkan dapat dikenal masyarakat secara luas sehingga dapat meningkatkan omzet penjualan. Perusahaan melakukan promosi secara aktif untuk menarik sebanyak mungkin konsumen, melihat di halaman akun perusahaan-perusahaan yang lain pada umumnya kita akan menemui berbagai macam bentuk penawaran, iklan, promosi, dan sebagainya yang tujuannya adalah untuk memasarkan produknya dan menarik pengunjung atau konsumen Semakin banyaknya bisnis produk es krim di Indonesia menumbuhkan persaingan penjualan, demikian dengan pemilik scoop \& skoops harus semakin giat dan inovatif dalam mempromosikan produk es krimnya. Scoop \& skoops merupakan toko es krim yang menyediakan penjualan online menggunakan media sosial instagram sebagai media untuk mempromosikan, unggahan foto produk-produk dengan berbagai macam varian yang dimiliki diharapkan dapat membangun kepercayaan konsumen agar tetap membeli produk scoop \& skoops.

Scoop \& Skoops adalah pelaku bisnis yang besar maka dari itu strategi komunikasi pemasaran mempunyai peran yang sangat penting untuk mencapai tujuan scoop \& skoops dan juga dalam menggembangkan usahanya. Hal ini juga didukung oleh pendapat Swastha dalam buku komunikasi pemasaran yaitu strategi adalah serangkaian besar yang menggambarkan bagaimana perusahaan harus beroperasi untuk mencapai tujuannya (Afrilia, 2018). Hubungan strategi dan pemasaran menjadi penting dalam dunia bisnis, karena pada hakikatnya hubungan ini merupakan langkah - langkah kreatif yang berkesinambungan yang diupayakan oleh sebuah perusahaan untuk mencapai target pemasaran terbaik dalam rangka mewujudkan kepuasan konsumen secara maksimal (Scoop.and.skoops, 2020).

Strategi promosi merupakan kegiatan bauran pemasaran yang terakhir. Dalam menghadapi persaingan perusahaan memerlukan strategi promosi untuk dapat memperkenalkan produknya dan menarik perhatian konsumen. Promosi sangat penting untuk keberhasilan pemasaran. Menurut (Rangkuti, 2013), Kegiatan promosi, bagi banyak perusahaan, merupakan kegiatan investasi yang sangat kritis melalui kegiatan pemasaran. Tanpa promosi maka konsumen akan sulit untuk mengetahui produk yang 
dijual oleh perusahaan. Strategi pelaksanaan promosi merupakan langkah-langkah yang secara berurutan dari awal sampai akhir dalam proses mempromosikan suatu produk, yaitu melalui periklanan yang kemudian diikuti dengan kegiatan promosi lainnya, diantaranya personal selling, promosi penjualan, dan publisitas (Rigawa, Wirasari, \& Desintha, 2015). Promosi dipandang sebagai kegiatan komunikasi pembeli dan penjual dan merupakan kegiatan yang membantu dalam pengambilan keputusan dibidang pemasaran serta mengarahkan dan menyadarkan semua pihak untuk berbuat lebih baik, (Susiladewi, 2020).

Promosi yang dilakukan scoop \& skoop dengan memanfaatkan media sosial instagram tersebut diharapkan juga dapat membangun brand image perusahaan dengan begitu produk yang dimiliki dapat menjadi pilihan para penggemar es krim, berdasarkan uraian latar belakang penelitian ini peneliti akan melakukan penggalian data dan observasi berkaitan dengan Strategi Scoop Dan Skoop Dalam Membangun Brand Image Sebagai Bentuk Komunikasi Pemasaran. Lokasi penelitian yang dilakukan peneliti di tempat scoop \& skoops yang berlokasi di jalan Ciwastra no. 184A, Mekarjaya, Kecamatan Rancasari di wilayah Kota Bandung, Provinsi Jawa Barat. Pada akun media sosial instagram @scoop.and.skoops. Peneilitian ini bertujuan untuk mengetahui bagaimana usaha akun media sosial instagram @scoop.and.skoops dalam membangun brand image.

\section{Metode Penelitian}

Penelitian strategi scoop \& Skoop dalam membangun brand image Sebagai bentuk komunikasi pemasaran ini didesain secara kualitatif, peneliti menentukan desain ini berdasarkan tema yang diangkat, setelah adanya observasi awal, dan berdasarkan tujuan penelitian yang sudah ditentukan. Penelitian yang peniliti susun ini menggunakan teknik pengumpulan data; 1 . Wawancara secara mendalam; wawancara ini peneiliti lakukan kepada para informan yang sudah peneliti tentukan dan disesuaikan dengan tema, Informan dalam penelitian ini ditentukan menggunakan purposive sampling. 2. Studi pustaka; pengumpulan data ini peneliti mencari informasi berkaitan dengan tema penelitian melalui buku, jurnal ilmiah, dan arsip dari scoop \& skoop yang nantinya data digunakan untuk melengkapi data utama, 3. Dokumentasi; penumpulan data dengan cara mendokumentasikan kegiatan pemasaran promosi, maupun kegiatan lainnya yang masih terdapat korelasi dengan tema penelitian.

Paradigma pendekatan dalam penelitian ini adalah metode deskripstif, menurut (Sugiyono \& deskripstif, 20016) menyatakan bahwa metode deskriptif adalah suatu metode yang digunakan untuk menggambarkan atau menganalisis suatu hasil penelitian tetapi tidak digunakan untuk membuat kesimpulan yang lebih luas. Penelitian deskriptif berusaha memberikan gambaran yang cermat dan lengkap tentang obyek yang diteliti. Penelitian kualitatif deskriptif ini sejalan dengan tujuan penelitian yang peneliti tentukan diawal, tujuan ini juga menentukan bagaimana mengolah atau menganalisis hasil penelitian yang peneliti hasilkan berdasarkan metode pengumpulan data tersebut.

\section{Hasil dan Pembahasan \\ Gambaran Umum Scoop \& Skoops}

Scoop \& Skoops ini berdiri pada tanggal 21 Juni 2018, Scoop \& Skoops adalah unit bisnis dari Amanda group pada saat itu korporat melakukan riset untuk mengembangkan sayap Amanda group dan memutuskan untuk membuka usaha baru yaitu Es krim. Berlokasi di kota Bandung, Scoop \& Skoops lahir menjadi sebuah merk 
dagang baru dengan dibawah naungan PT. Gerbang Mas Bersama dan diresmikan pada tanggal 29 September 2018, Scoop \& Skoops menjelma menjadi sebuah cafe Es krim pertama di Indonesia dengan menganut konsep industrial didalamnya.

Nama Scoop \& Skoops tersebut terinspirasi dari salah satu alat yang digunakan seorang scoopers (julukan bagi panyaji es krim ) atau lebih dikenal dengan Ice Scoop dengan metode menyisir Es krim secara berulang, diharapkan para pelanggan akan datang dan menikmati prodak Es krim Scoop \& Skoops secara berkelanjutan. Dalam mengenalkan 24 jenis varian rasa Es krim yang telah kami siapkan setiap harinya dari yang bercita rasa lokal hingga cita rasa internasional kami menggunakan platform media sosial Instagram sebagai alat untuk memperkenalkan produk-produk kami dengan nama akun @Scoop.and.skoops dan saat ini followers pada akun Instagram kami sudah mempunyai sebayak 13,5 ribu followers.

\section{Informan}

Informan dalam penelitian ini ditentukan menggunakan purposive sampling. Purposive sampling adalah teknik pengambilan sampel sumber data dengan pertimbangan tertentu. Pertimbangan tertentu adalah orang tersebut yang dianggap paling tahu tentang apa yang kita harapkan, atau mungkin dia sebagai penguasa sehingga akan memudahkan peneliti menjelajahi objek atau situasi sosial yang diteliti. Peneliti melakukan observasi di lapangan untuk menentukan informan yang memahami keadaan dan kondisi scoop \& skoop dan diharapkan peneliti informan tersebut dapat mengungkap data penelitian berkaitan dengan komunikasi pemasaran dan brand image diantaranya yaitu marketing staff dan social media officer. Marketing staff dan social media officer bekerja dalam tatanan struktur organisasi Scoop \& Skoops sebagai yang dianggap mengetahui bagaimana menjalankan pemasaran melalui media sosial dan mengetahui traffic dan insight, maka dari itu peneliti menjadikan sebagai key informan (informan kunci) dalam penelitian ini. Dan informan pendukung dalam penelitian ini yaitu 2 followers aktif media sosial Instagram Scoop \& Skoops yang pernah mengikuti kompetisi yang diadakan oleh Scoop \& Skoops

Tabel. 1 Data Informan

\begin{tabular}{|c|c|c|c|c|c|}
\hline $\begin{array}{l}\mathbf{N} \\
\mathbf{O}\end{array}$ & Informan & $\begin{array}{c}\text { Jenis } \\
\text { Kelamin }\end{array}$ & Usia & Pekerjaan & $\begin{array}{c}\text { Akun } \\
\text { Instagram }\end{array}$ \\
\hline 1. & $\begin{array}{l}\text { Fahmi } \\
\text { Akmal }\end{array}$ & Laki-laki & $\begin{array}{l}25 \\
\text { Tahu }\end{array}$ & $\begin{array}{l}\text { Marketing } \\
\text { staff }\end{array}$ & $@]_{m}{ }^{f a}$ \\
\hline 2. & $\begin{array}{l}\text { Muwhor } \\
\text { Tiwi }\end{array}$ & $\begin{array}{l}\text { Perempu } \\
\text { an }\end{array}$ & $\begin{array}{c}n \\
19 \\
\text { Tahu } \\
n\end{array}$ & $\begin{array}{l}\text { crann s. } \\
\text { Mahasiswa }\end{array}$ & @uwilpalvin \\
\hline 3. & $\begin{array}{l}\text { Sandy } \\
\text { Pratama }\end{array}$ & Laki-laki & $\begin{array}{c}33 \\
\text { Tahu }\end{array}$ & Supir Grab & $\begin{array}{c}\text { @sandiprata } \\
\text { ma0708 }\end{array}$ \\
\hline
\end{tabular}

\section{Strategi Scoop Dan Skoop Dalam Membangun Brand Image}

Branding mempunyai peranan yang penting dalam sebuah pemasaran produk, adanya branding menjadikan produsen menunjukan produknya mempunyai kualitas yang terpercaya. Branding sangat diperlukan oleh produsen karena dengan branding produsen sedang membuat target konsumen menjadi mengenal atau familiar dengan 
produk yang ditawarkan, dan hal itu akan menumbuhkan kepercayaan bagi siapa saja yang menjadi target branding.

Menurut (Yuniar Nugroho, 2012) citra merek (Brand image) adalah apa yang dipersepsikan oleh konsumen mengenai sebuah merek. Untuk itulah pembangunan sebuah citra merek, terutama citra yang positif menjadi salah satu hal yang penting. Memanfaatkan media sosial untuk berhubungan dengan pelanggan perusahaan dapat meningkatkan loyalitas brand. Setiap perusahaan dalam membangun brand tentunya memiliki caranya masing-masing. Membangun brand merupakan salah satu cara yang paling penting dilakukan oleh toko Es krim Scoop \& Skoops agar meningkatkan nilai penjualan terhadap produk yang ingin dipasarkan. Tentunya produk yang akan di pasarkan haruslah berkualitas. Scoop \& Skoops merupakan salah satu toko Es krim yang memiliki produk yang berkualitas dengan menawarkan 36 varian rasa Es krim.

“ Kita Es krim tapi menawarkan berbagai macam varian rasa terus juga dengan harga yang relatif terjangkau tapi rasanya berkualitas, karena produk berkualitas itu penting ya terus juga di Instagram kita lebih ke varian rasa ya untuk membangun brand imagenya dengan selogan Es krim dengan cita rasa lokal, gitu karena Es krim kita itu ada macam macam rasa lokal contohnya ada rasa rujak gitu pokonya ada es krim rasa lokal gitu disin nah lalu itu kita update ke Instagram kita, dan bisa online order kok lewat link Instagram kita”.

Kutipan tersebut merupakan hasil wawancara peneliti dengan Fahmi marketing Scoop \& Skoops yang juga mengelolah akun Instagram Scoop \& Skoops.

Produk yang dijual oleh Scoop \& Skoops adalah Es krim semi gelato yang tidak mengandung gelatin dan teknik pembuatan Es krim Scoop \& Skoops ini tidak sama dengan pembuatan Es krim gelato lainnya karena hanya bahan bakunya saja yang serupa dengan Es krim gelato. Produk yang Scoop \& Skoops sediakan merupakan olahan orisinil milik Scoop \& Skoops dengan menggabungkan dan berinovasi terhadap bauran rasa-rasa unik sperti Rujak, Tape Ketan, Brownies, Bandrek, dan Wijen Hitam. Dan rasa-rasa unik tersebut Scoop \& Skoops menambahkan hiasan guna mempercantik tampilan produk Es krim tersebut dengan Marshmellow, Choco Chips, Choco Stick dan lain sebagainya.

Scoop \& Skoop pun menyediakan beberapa pilihan wadah seperti Cup, Cone, dan special Cup. Kisaran harga yang ada pada produk Scoop \& Skoops ini di hitung menggunakan scoop Es krimnya dan minimal pembelian yaitu 2 scoop dengan harga 16 ribu rupiah harga tersebut memang memiliki harga yang cukup standar untuk dikalangan remaja atau saku pelajar.

Berdasarkan wawancara dan penelusuran tersebut peneliti menemukan bahwa Scoop \& Skoops dalam membangun brand image melalui instagram yang pertama adalah dengan memposting varian rasa Es krim lokal yang di pasarkan dengan harga yang relatif murah namun berkualitas, didapatkan pula informasi bahwa Scoop \& Skoops menyediakan link yang terhubung dengan whatsapp pada bio akun Instagram Scoop \& Skoops untuk melakukan order secara online.

Selain itu akun Instagram Scoop \& Skoops dalam membangun brand yang ke dua yaitu dengan memberikan testimoni-testimoni pelanggan .

"Kalo testimoni itu harus banget, soalnya kan itu salah satu daya tarik untuk konsumen lainnya, tapi gak semua kami repost story gramnya yang konsumen tag ke Instagram Scoop \& Skoops, pastinya akan kami pilih yang foto Jurnal Indonesia Sosial Teknologi, Vol. 2, No. 1, Januari 2021 
produknya terlihat jelas, fotonya bagus dan menarik”. (kutipan hasil wawancara dengan informan).

Menurut peneliti testimoni yang dilakukan Scoop \& Skoops merupakan salah satu yang paling penting untuk membuktikan kepada konsumen-konsumennya, yang terutama belum pernah membeli produk Scoop \& Skoops, kehadiran testimoni ini mampu menjadi daya tarik untuk konsumen lainnya. Meskipun setiap testimoni yang di tag ke Instagram Scoop \& Skoops tidak semua di repost, karena penempatan testimoni pada story gram harus rapih dan terukur dengan begitu akan menjadi salah satu cara agar citra Scoop \& Skoops menjadi baik di media sosial Instagram agar brand Scoop \& Skoops juga terus meningkat.

Selain itu dalam membangun brand image, yang dilakukan akun Instagram Scoop \& Skoops agar banyak orang yang mengenal Scoop \& Skoops yaitu menggunakan seorang influencer instagram yang sering disebut selebgram (selebriti instagram). Influencer marketing mampu meningkatkan brand awareness bisnis karena influencer merupakan mereka yang memiliki banyak followers dan memiliki pengaruh yang kuat terhadap followers mereka sehingga mereka dapat mempengaruhi followers mereka untuk mencoba dan membeli sebuah produk.

“Ambasador yang kita pilih itu terkenalnya di Instagram bukan televisi jadi ya karena itu juga salah satu alasannya kita menggunakan Instagram, followers sebanyak 13,5 itu kita terbantu dari ambasador dari hubungan dengan mereka jadi followers terus menambah, terus kita pilih juga ambasadornya itu yang kribo karena kita miripkan gitu sama bentukan Es krim yang bulat menumpuk dari scoop nya itu loh jadi ada nicko, edi brokoli, terus bayu kibo itu ke 3 ambasadornya”. (kutipan wawancara dengan informan).

Menurut pengamatan peneliti dari wawancara di atas bahwa ambasador oleh selebritis Instagram (selebgram), yang menjadi cara ke tiga yang dilakukan Scoop \& Skoops dalam membangun brand image melalui Instagram untuk membranding juga bisa untuk mendorong calon pembeli untuk melakukan pembelian karena selebiritis Instagram (selebgram) memiliki andil yang besar dalam mempengaruhi fans dan followers-nya untuk mengikuti gaya hidup yang ditampilkan oleh idolanya.

Berdasarkan pengamatan peneliti selama dilapangan dan juga hasil wawancara dari informan bahwa akun media sosial Instagram Scoop \& Skoops dalam membangun brand image-nya yang dilakukan Scoop \& Skoops yaitu adalah dengan memberikan produk yang berkualitas dengan harga yang cukup terjangkau, selanjutnya testimonitestimoni dari para pelanggan Scoop \& Skoops, dan kemudian menggunakan selebritis Instagram (selebgram) sebagai orang ketiga yang mampu memberikan dampak yang baik untuk membranding Scoop \& Skoops.

Langkah-langkah membangun citra merek menurut (Rangkuti, 2013) yaitu :

1. Memiliki positioning yang tepat

Merek harus dapat menempati atau memposisikan diri secara tepat untuk selalu menjadi nomer satau dan utama dibenak konsumen.

2. Memiliki brand value yang tepat

Produsen harus membuat brand value yang tepat untuk membentuk brand personality yang baik terhadap merek untuk membuat merek semakin bernilai dan kompetitif di benak konsumen.

3. Memiliki konsep yang tepat 
Untuk mengkomunikasikan brand value dan postioning yang tepat maka dibutuhkan konsep yang tepat sesuai sasaran baik terhadap produk, segmentasi pasar, cara memasarkan, target pasar, dan kulitas pelayanan.

Peneliti akan menganalisa dan memaparkan lebih sistematis dan terstruktur mengenai akun media sosial Instagram Scoop \& Skoops dalam membangun brand image berdasarkan langkah-langkah membangun citra merek menurut (Rangkuti, 2008) tersebut yaitu :

1. Akun Instagram @scoop.and.skoops sudah berada ditengah hati masyarakat, karena dengan selogan "Es krim dengan cita rasa lokal” Scoop \& Skoops telah membawa kesegaran baru lewat jutaan sensasi Es krim yang dapat dinikmati dan terjangkau bagi masyarakat luas. Tentunya dengan nilai-nilai eksklusivitas produk dan standarisasi yang Scoop \& Skoops terus junjung setingginya. Pada aktivitasnya akun Instagram @scoop.and.skoops memposting berbagai varian rasa Es krim yang ditawarkan dengan menggunakan fitur-fitur yang menarik, akun Instagram @scoop.and.skoops pun menyediakan link order online guna untuk mempermudah konsumen melakukan pemesanan.

2. Akun Instagram @scoop.and.skoops memiliki tampilan secara profesional sehingga dapat menampung seluruh feed back pelanggan yang memiliki saran dan cara pandang sendiri dalam menilai produk yang Scoop \& Skoops tawarkan dengan menampilkan halaman khusus atau fitur Q and A , tag line, dan testimoni pelanggan pada akun Instagram @scoop.and.skoops. dengan itu Scoop \& Skoops dapat mengetahui langkah-langkah untuk membangun brand value yang baik untuk membuat merek semakin bernilai dan kompetitif dibenak konsumen.

3. Akun Instagram @scoop.and.skoops sudah memiliki konsep yang tepat yaitu produk-produk yang di posting pada Instagram Scoop \& Skoops merupakan produk Es krim olahan orisinil milik Scoop \& Skoops yang dibuat dengan berbagai varian rasa loka dan internasional dan dikemas dengan warna yang unik, produk-produk tersebut dibandrol dengan harga yang terjangkau sesuai dengan segmentasi dan target pasar yang telah dirancang oleh Scoop \& Skoops. Akun Instagram @scoop.and.skoops juga berkolaborasi dengan influencer Instagram untuk memasarkan produk-produk yang dimiliki Scoop \& Skoops, dan akun Instagram @scoop.and.skoops merespon konsumen melalui kolom komentar, pesan langsung, hastag, mention, dan tag people untuk kualitas pelayanan.

\section{Kesimpulan}

Akun media sosial Instagram Scoop \& Skoops dalam membangun brand image dengan cara memberikan produk yang berkualitas dengan harga yang cukup terjangkau, selanjutnya testimoni-testimoni dari para pelanggan Scoop \& Skoops, dan kemudian menggunakan selebritis Instagram (selebgram) sebagai orang ketiga yang mampu memberikan dampak yang baik untuk membranding Scoop \& Skoops. 


\section{Bibliography}

Afrilia, Ascharisa Mettasatya. (2018). Digital Marketing Sebagai Strategi Komunikasi Pemasaran "Waroenk Ora Umum” Dalam Meningkatkan Jumlah Konsumen. Jurnal Riset Komunikasi, 1(1), 147-157.

Hermawan, Agus. (2012). Komunikasi pemasaran. Jakarta: Erlangga.

Machfoedz, Mahmud. (2010). Komunikasi pemasaran modern. Yogyakarta: Cakra Ilmu, 139.

Nasrullah, Rulli. (2015). Media sosial: Perspektif komunikasi, budaya, dan sosioteknologi. Bandung: Simbiosa Rekatama Media, 2016, 2017.

Rangkuti, Freddy. (2008). ANALISIS SWOT: Teknik Membedah Kasus Bisnis cetakan ke lima belas, Penerbit PT. Gramedia Pustaka Utama Jakarta.

Rangkuti, Freddy. (2013). Strategi promosi yang kreatif dan analisis kasus. Gramedia Pustaka Utama.

Rigawa, Aldo, Wirasari, Ira, \& Desintha, Siti. (2015). Perancangan Promosi Wisata Danau Linow Di Sulawesi Utara. EProceedings of Art \& Design, 2(1).

Scoop.and.skoops. (2020). Scoop.and.skoops Instagram.

Sugiyono, M. P. P., \& Kuantitatif, P. (20016). Kualitatif, dan R\&D, Bandung: Alfabeta. Cet. VII.

Susiladewi, Susiladewi. (2020). PENGARUH HARGA, PROMOSI DAN KUALITAS PELAYANAN TERHADAP KEPUASAN KONSUMEN DI CAFÉ KUPI DATU BANJARBARU. Al-KALAM JURNAL KOMUNIKASI, BISNIS DAN MANAJEMEN, 7(2), 45-64.

Turban, Efraim, Outland, Jon, King, David, Lee, Jae Kyu, Liang, Ting Peng, \& Turban, Deborrah C. (2017). Electronic commerce 2018: a managerial and social networks perspective. Springer.

Utomo, Dea Anggraeni. (2013). Motif pengguna jejaring sosial Google+ di Indonesia. Jurnal E-Komunikasi, 1(3).

YUNIAR NUGROHO, FARID. (2012). PENGARUH CITRA MEREK DAN KEPUASAN PELANGGAN TERHADAP LOYALITAS KONSUMEN (Studi Kasus Perilaku Konsumen Rumah Makan Gudeg Pawon Di Janturan Umbulharjo). UPN" Veteran" Yogyakarta. 